\title{
Eğitim Bilimlerinde Epistemoloji Araştırmaları: Düne, Bugüne ve Gelecek Perspektiflere Eleștirel Bakış
}

\section{Epistemological Research in Educational Sciences: Critical Investigation of Past, Present and Future Perspectives}

\author{
Eralp BAHÇIVAN*
}

\begin{abstract}
Öz: Bu araştırma yaklaşık olarak elli yıllık bir zamana yayılan epistemoloji alanındaki çalışmaların eleştirel bir derlemesidir. Kişisel epistemoloji, bireylerin öğrenme-öğretme inançları ve davranışları üzerinde etkili olan temel inançlarını içermektedir. Epistemolojik inançların öğrenme-öğretme açısından merkezi konumda olması eğitim alanında yapılan ilişkilendirme çalı̧̧malarına önemli bir ivme kazandırmıştır. Ancak ülkemizde bireysel epistemoloji alanındaki perspektifleri ve modelleri, epistemolojik çalışmalarının neden önemli olduğunu ve gelecekte bu alanda ne gibi çalışmalar yapılabileceğine yönelik eğilimleri eleştirel bakış açısı ile derleyen bir çalışmayla karş̧laşılmamıştır. Böyle bir çalışmanın özellikle bilimsel arenaya yeni katılan araştırmacılara bu alandaki temel kavramları kıyaslamalar yaparak tanıtmasının gelecekte ülkemizde epistemoloji bağlamında yapılacak bilimsel araştırmalara katkısı olacağı düşünülmüștür.

Anahtar Sözcükler: Epistemoloji, kişisel epistemoloji, epistemolojik inançlar
\end{abstract}

\begin{abstract}
This study is a critical review of epistemology related scientific research which expands on approximately fifty years. Personal epistemology involves individual's core beliefs effective on their teaching-learning beliefs and behaviors. This centrality of epistemological beliefs in terms of teaching and learning has accelerated the scientific research on this area. However, in national literature there is not any review study presenting critics related to epistemological perspectives and models, importance of epistemological studies and future trends in this area. Such a study is valuable since presenting future researchers with the basic concepts of this arena. Therefore, this study may contribute to awareness of researchers, so may give acceleration to the number of studies conducted about personal epistemology.

Keywords: Epistemology, personal epistemology, epistemological beliefs
\end{abstract}

\section{Giriş}

Epistemoloji, hemen hemen tüm bilim alanlarında olduğu gibi kökenini felsefeden alır; bilgi felsefesi anlamına gelir ve felsefenin 4 önemli uğraş alanından bir tanesidir. Bu alanda yapılan çalışmalar Antik Yunan dönemi ile başlamış olsa da güçlenmesi için 17. yüzyılı bekleyecektir. Çünkü bu yüzyılda moderniteye geçiş başlamıştır ve bilgi, kültürü belirleyen çığır açıcı etki gücüne ulaşmıştır. Ancak felsefi anlamda epistemoloji eğitim bilimlerinde ele aldığımız bağlamları dikkate almaz. Felsefinin alanına giren epistemoloji, bilgiyi salt bilgi olduğu için ele alır ve inceler, insan zihnindeki oluşum süreçleri ile ilgilenmez (Cevizci, 2010). Oysa eğitimciler bireylerin bilişsel yapılarını nedensellikleri ile inceler ve bu bilişsel yapıları ya da sistemleri istendik yönde etkilemeyi hedefler.

Epistemolojinin eğitim bilimlerine kazandırılması bilişsel psikoloji alanında yapılan bilimsel çalışmalar sayesinde gerçekleşmiştir (Hofer ve Pintrich, 2002). 1970'li yıllardan itibaren başlayan bu geçiş dönemi boyunca ulusal ve özellikle uluslararası arenada epistemolojik değişkenler eğitsel açıdan hayati öneme sahip olan birçok farklı değişken (özyeterlik inançları, kavramsal öğrenme ve değişim, benlik vb.) ile ilişkilendirilmiştir. Çalışmaların sonuçları bireylerin epistemolojik inançlarının ya da bakış açılarının öğrenme ve öğretme açısından merkezi bir öneme sahip olduğunu göstermiştir (Hofer ve Pintrich, 1997).

\footnotetext{
* Yrd. Doç. Dr., Abant İzzet Baysal Üniversitesi, Eğitim Fakültesi, Bolu, e-posta: eralpbahcivan@ hotmail.com
} 
Çağımızda gelişen teknolojiler sayesinde bilgi edinme imkânlarının yanında bilgi kirliliği de artmıştır. Dolayısıyla bireylerin bilgiyi nasıl elde ettikleri, hangi gerekçelerle ve neden o bilginin doğru olduğuna inandıkları, bilginin ya da bilmenin kendi zihinsel yapıları içerisinde nasıl tanımlandığı gibi temel sorular önceki yüzyıllara oranla çok daha önemli hale gelmiştir. Bu makale, bahsi geçen temel sorulara cevap bulduğumuz ve artık eğitim bilimlerinin de temel uğraşlarından birisi haline gelen epistemolojiye ilişkin dünden bugüne yapılan bilimsel çalışmaların eleştirel bir bakış açısı ile derlemesidir. Çalışmanın bilimsel arenaya henüz girmekte olan yeni araştırmacılara ve epistemolojiye ilgi duyan bilim insanlarına Türkçe yayımlanmasından dolayı katkıda bulunacağı düşünülmektedir. Bu çalışmada literatür sadece özetlenmeyecek, eleştirel bir bakışla sunulacaktır. Eğitim bilimlerinde epistemolojinin eleştirel derlemesinin yapıldığı bu makalede aşağıdaki sorulara cevap üretilmeye çalışılacaktır:

1) Epistemoloji alanında hangi perspektifler (ya da modeller) vardır?

2) Epistemoloji neden önemlidir?

3) Epistemoloji alanında gelecek perspektifler hangi değişkenlere odaklanabilir?

\section{Perspektifler}

\section{Gelişimsel Perspektif}

$\mathrm{Bu}$ perspektifin lideri her ne kadar Perry (1970) gibi görünse de arka planda aslında Piaget (1970) yer almaktadır. Piaget (1970) bilindiği gibi bilişsel gelişim üzerine çalışmış ve yapılandırmacı öğrenme kuramının kurucusu olarak kabul görmüş bir psikologdur. Onun bilişsel gelişim yaklaşımında 'bilme' önemli bir problem olarak ele alınmış ve epistemik problem olarak isimlendirilmiştir. Çalışmalarında 'bilginin kaynağı nedir?' ve 'bilginin doğruluğuna yönelik muhakeme nasıl gelişir?' gibi soruların cevaplarını bireylerin bilişsel gelişimleri ile ilişkilendirmiş ve epistemik gelişimin temelinde bireylerin biyolojik gelişiminin yattığını iddia etmiştir. Onun çalışmalarından etkilendiği görülen Perry (1970) ise öğrencilerin sosyal olaylara ve entelektüel durumlara karşı bakış açılarını inceleyen 10 yıllık sürece yayılan 2 farklı çalışma gerçekleştirmiştir. Perry'nin çalışmalarında tek veri kaynağ görüşme sorularına verilen cevaplardır. Bu çalışmaların örneklemi Harward Üniversitesi'ndeki erkek öğrencilerdi. Sonraları sadece beyaz erkek elitlerden oluşan bu örnekleme dayanılarak ortaya konulanlar çok eleştirilmiş olsa da araştırma sonuçları gerçekten dikkat çekiciydi (Belenky, Clinchy, Goldberger ve Tarule, 1986). Perry'e (1970) göre bireyler biyolojik gelişim ve sosyal etkileşimler sayesinde bilginin ve bilmenin doğasına yönelik olarak birbirini takip eden 9 aşamalı bakış açısına sahip olmaktadır. Bu noktada okuyucunun uyarılması gereken önemli bir husus var: Perry, burada 'bakış açısı' olarak tercüme edilen kavrama 'pozisyon' (position) demiştir, ancak 'pozisyon' bireylerin bakış açıları anlamında kullanılmıştır. Perry'nin ortaya koyduğu ve birbirini takip eden bu 9 farklı bakış açısı çok kısa bir süre sonra 4 başlık altında toplanmıştır: ikicil (dualistic), çoğulcu (multiplistic), göreli (relativistic) ve görelilikte kararlı olma (commitment within relativism).

İkicil bakış açısına sahip bireyler herhangi bir bilgiyi kesinlikle doğru ya da yanlış şeklinde algılamaktadırlar. Bu evredeki bireyler bilginin kaynağını da otoriteler (öğretmen, anne-baba, bilim insanı, vb.) olarak görürler. Çoğulcular ise gerçeğin ve bilginin farklı otoriteler tarafindan farklı şekillerde ortaya konabileceğini kabul ederler. Onlara göre zaman zaman bazı belirsizlikler ortaya çıksa da tek bir gerçek hala elde edilebilir ve bu gerçeğin kaynağ 1 yine otoritelerdir. Göreliler ise artık bilginin ve bilme eyleminin kaynağında kendisini görenlerdir. Bunlara göre bilgi bağlamsaldır ve herkes farklı gerekçelerle farklı gerçeklere ya da farklı bilgilerin doğruluğuna inanabilirler. En gelişmiş bakış açısı ise görelilikte kararlı olma hali olarak isimlendirilmiştir. Bu evredeki bireylerin göreli olanlardan en önemli farkı kararlı olmalarıdır. Başka bir deyişle bunlar farklı insanların farklı bilgileri doğru bulmasının anlaşılır olduğunu kabul etmekle birlikte bu farklı doğrulardan birisinin diğerlerine göre gerçeğe daha yakın olduğuna inanırlar. Bilginin kaynağında kendilerini görürler ve bilginin ve bilme eyleminin farklı yollarla gerekçelendirilmesinin gerçeğe ulaşma konusunda kendilerini kararlı hale getirdiğini düşünürler. Perry'nin (1970) ortaya koyduğu bu epistemolojik bakış açıları 
biyolojik gelişim, sosyal etkileşim ve eğitimin sayesinde ikicilden görelilikte kararlı olma haline doğru ilerlemektedir ve bu 4'lü evre yaklaşık olarak ergenlik döneminden üniversite eğitimin tamamlandığı zaman aralığına kadar olan hayatımızı kapsadığı iddiasındadır.

Perry'nin ortaya koyduğu gelişimsel perspektife dayalı epistemolojik bakış açısı tanımlaması yapılandırmacı yaklaşım ile de uyum içerisinde olduğu için özellikle batı toplumlarında yaygın kabul gördü. Bu yaklaşımı takip eden birçok farklı araştırmacı grubu benzer modeller ortaya koymuştur. Örneğin Belenky ve diğerleri (1986), Perry'nin örneklemini sadece elit-beyaz erkeklerden oluştuğu için eleştirmiş ve benzer bir çalışmayı kadınlardan oluşan bir örneklemle gerçekleştirmiştir. Baxter Magolda (1992) da cinsiyet bağlamında benzer katkılarda bulunmuştur. King ve Kitchener'in (1994) yansitıc1 yarg1 modeli ise (reflective judgement model) Perry'nin yaklaşımını benimser ancak ikircikli durumlara (ill-structured problems) odaklanmaktadır. Lise öğrencilerinden orta yaşlı bireylere kadar geniş bir örneklem ile gerçekleştirilen 15 yıllık mülakatların neticesinde açığa çıkan bir modeldir. Bu model epistemik biliş (epistemic cognition) üzerine yoğunlaşmış ve epistemik bilişin kendisini gösterdiği alan olarak ta ikircikli durumlarda insanların fikirlerini nasıl gerekçelendirdiği üzerine yoğunlaşmıştır. Analizler neticesinde 7 aşamalı gelişimsel bir model açığa çıkmıştır. Buna göre ilk evrelerde bilgiye ilişkin olarak bireyler kendi bildiklerini mutlak doğru olarak kabul etmekte, ancak ilerleyen evrelerde bilginin ve gerçekliğin belirsizliği anlaşılmaya başlamaktadır. Sonraları, bireyler bilgiye yönelik farklı perspektifler olabileceğini dolayısıyla bilginin sübjektif bir yapı olduğunu kavramaktadır. En gelişmiş evredeki bireyler ise bilginin sürekli devam eden bir sorgulamanın neticesi olduğunu, bu sürecin gerçeğe öncekine göre her an daha da yaklaştığını kabul ediyorlar ve gerekçelendirmenin bilginin kabul edilmesindeki önemini vurguluyorlar. Gelişimsel bakış açısına sahip olanlar içinde önemli bir grubu da D. Kuhn ve ekibi oluşturmaktadır. Kuhn, Iordanou, Pease ve Wirkala'nın (2008) epistemolojik modeli Perry'nin modeline çok benzemektedir. Perry'den farklı olarak Kuhn'un modelinde 3 aşamalı bakış açısı vardır: mutlakçı (absolutist), çoğulcu (multiplist) ve değerlendirmeci (evaluativist). Bu evrelerden ilki Perry’nin ikicil bakış açısına, ikincisi göreli bakış açısına ve sonuncusu görelilikte kararlı olma bakış açısına çok benzemektedir.

Yukarıda gelişimsel modellerin hepsinden olmasa da önemli olanlarından söz edilmiştir. Ancak hala bireylerin gelişimsel evrelerdeki geçişleri nasıl sağladığı tam olarak açıklanmamıştır. Aslında bu modeller Piaget'nin bilişsel yaklaşımını benimsediği için temelde bilişsel denge-dengesizlik (cognitive equilibrium-disequilibrium) uyumu üzerine otururlar. Buna benzer bir kavramı Bendixen (2002) epistemik şüphe (epistemic doubt) şeklinde açıklamıştır. Bendixen'in yaptığı nitel araştırmalar göstermiştir ki sosyal bağlamlardaki etkileşimler bireylerin kendi epistemolojik inançlarından şüphelenmesine sebep olmaktadır. Epistemik şüphe yüzünden epistemolojik bir dengesizliğe düssen bireyler iki yoldan birisi ile dengeye gelirler. Birincisi, var olan epistemolojik inanç sistemini değiştirerek yeni bir bilişsel şema oluşturmaktır. İkincisi ise var olan şemayı korumak için otoritelerden (dini düşünce, eğitimli bireyler, vb.) destek almaktır. Bendixen'in çalışmaları özellikle üniversite çağındaki bireylerde sosyal etkileşimlerin arttığını ve epistemik şüphenin bu çağdaki bireylerde daha sık karşılaşılan bir durum olduğunu göstermiştir.

Bu başlığa noktayı koymadan önce bahsedilmesi gereken bazı noktalar var. Birincisi gelişimsel perspektife sahip olan araştırmacılar epistemolojiyi bilişsel bir bakış açısı, hatta bazen muhakemenin önemli bir unsuru olarak görmektedirler. Her ne kadar önceki paragrafta Bendixen epistemolojik inançlar ibaresini kullanmış olsa da gelişimsel perspektife sahip olanlar epistemolojiye inanç sistemi olarak bakmazlar. Onlar, insanların epistemolojik durumlarından bahsederken kişisel epistemoloji (personal epistemology) kavramını kullanmayı tercih ederler. İkincisi gelişimsel perspektife sahip olanlar hemen tüm çalışmalarında boylamsal nitel desenleri tercih etmişlerdir (Hofer ve Pintrich, 1997). En kısa süreli çalışmaları 5 yıldır ve genellikle görüşmeler yoluyla veri toplarlar. Kesitsel (anlık) nitel veri ile çalışan yok denecek kadar azdır. Gelişimsel perspektife sahip olanların hemen tamamı bilişsel psikologdur, dolayısıyla çalışmaları eğitsel açıdan önemli değişkenler ile yeterince ilişkilendirilmemiştir. Çünkü epistemolojiye bakış açıları kişisel epistemolojiyi geliştirmek değil onu anlamak şeklinde 
olmuştur. Bununla beraber hepsinin söylediği ortak bir ifade var: kişisel epistemoloji eğitim yoluyla gelişir. Ancak bu ifadenin altı dolu değildir çünkü eğitimin nasıl bir model ile kişisel epistemolojiyi geliştireceğine yönelik bir çalışmalarına rastlanmamıştır. Öte yandan geniş yaş aralıklarını dâhil ettikleri bilimsel çalışmalarda hepsi şu sonuca ulaşırlar: eğitim düzeyi arttıkça bireylerin epistemolojik bakış açıları güçlenmektedir (Hofer ve Pintrich, 1997; King ve Kitchener, 2004). Ancak eğitim düzeyi arttıkça bireylerin bilişsel gelişimleri biyolojik temelde zaten güçlenmektedir. Dolayısıyla onların hâlihazırdaki çalışmalarına bakarak kişisel epistemolojideki ilerlemelerin eğitsel müdahale yolu ile mi yoksa biyolojik gelişmeden mi kaynaklandığı anlaşılamaz. Son olarak, özenle altının çizilmesi gereken bir husus var. Yukarıda özetle bahsedilmiş olan tüm modeller batı kültüründe oluşturulmuştur. Veriler batı toplumunun verileridir dolayısıyla Türk kültürüne tam olarak uygun olduğunu düşünmek yanlış olacaktır. Moderniteden post-moderniteye çoktan geçilmiş bir çağda yaşıyoruz. Bilgi artık makro yerine mikro düzeylerde anlam kazanırken farklı kültürlerde açığa çıkarılmış ve nesnesi insan olan bir bilgiyi olduğu gibi kabul etmek beraberinde başka hataları da getirecektir.

\section{İnanç Sistemi Perspektifi}

Gelişimsel perspektifi takip eden araştırmacıların, kişisel epistemolojinin doğuştan itibaren sosyal etkileşim ve biyolojik gelişim temelinde ilerleme gösteren tek boyutlu (unidimensional) bilişsel bir yapı olduğuna yönelik iddiaları geniş bir kabul görmüş olsa da 90'ların başlarında hegemonyaları sarsılacaktır. Schommer (1990) kişisel epistemolojiyi çok boyutlu (multidimensional) bir inanç sistemi olarak açıklamıştır. Nicel ölçümler (63 maddeli Likert ölçek) yolu ile de ortaya attı̆̆ iddiayı küçümsenmeyecek ölçüde desteklemiş̧tir (Schommer, 1990, 1994). Schommer'e göre kişisel epistemoloji 5 boyutlu bir inanç sistemidir: bilginin kesinliği (certainty), bilginin basitliği (simplicity), bilginin kaynağı (source), öğrenme hızı (quick learning) ve doğuştan yetenek (innate ability). Bu boyutları tanımlamadan hemen önce gelişimsel perspektifi savunan bilim insanlarının önemli bir eleştirisini belirtmek gerekir. Schommer' in biraz önce belirtilen son iki boyutu bilgi ya da bilmenin doğası ile ilgili değildir. $\mathrm{Bu}$ iki boyut doğrudan öğrenme ile ilgilidir. Dolayısıyla kişisel epistemoloji kapsamına alınamaz (Hofer ve Pintrich, 1997). Geçen zaman içinde Schommer-Aikins (2004) bu eleştirileri haklı görmüş ve ilk 3 boyutta yer alan epistemolojik inanç boyutlarının öğrenme ile ilgili olan diğer iki boyutu etkilediğini ifade etmiştir. Dolayısıyla, burada 5 boyutun tamamı değil kişisel epistemolojiyle ilgili olan ilk üçü tanımlanacaktır. Ancak boyutların tanımlarını vermeden önce bir noktanın daha üzerinde durmak gerekir. Schommer'e $(1990,1994)$ göre bireylerin epistemolojik inançları bu 3 boyut üzerinde süreklilik arz eder. Başka bir deyişle bireylerin inançları naif (naïve)-sofistike (sophisticated) karşıtlı̆̆ bakımından zayıf bir epistemolojik inanç iken sofistike taraf nitelikli inancı temsil eder. Bireyler ölçek üzerinde kendi tercihlerini yaparken bu ikiliğin farkında olmadan kendi seçimlerini işaretlerler.

Şimdi boyutları tanımlayabiliriz. Bilginin kesinliği boyutu aslında bilginin değişmezliğine odaklanan boyuttur. Bu boyutta naif inançlara sahip olan bireyler bilginin kesin doğru olduğuna ve değişmeyeceğine inanırlar. Öbür taraftan sofistike inanışa sahip olan bireyler bilginin değişen ve yenilenen bir oluşum olduğunu kabul ederler. Bilginin basitliği boyutu ise adından da anlaşılacağı gibi bilginin ne kadar basit ya da karmaşık bir yapı olduğuna yönelik inançları sorgular. Naif bireyler bilginin basit ve birbirinden kopuk yapılar içerdiğine inanırken sofistike inanca sahip olanlar bilginin karmaşık ve birbiriyle ilinti mikro parçalar içerdiğine dolayısıyla tam olarak kavranmasının zor olduğuna inanırlar. Son olarak bilginin kaynağı boyutu bilgi ya da bilmenin doğasındaki otoriteleri sorgular. Naif inançlar bilginin kaynağını öğretmen, ders kitabı, bilim insanı gibi kaynaklar olarak kabul ederken, sofistike olanlar bilginin ya da bilmenin kaynağında bireyin kendisini görmesi anlamına gelir (Sinatra, Kienhues ve Hofer, 2014). Hofer ve Pintrich (1997) derleme literatürdeki bütün epistemolojik modellerin karşılaştırmasını yaparlar ve gelişimsel perspektifin bilmenin gerekçelendirilmesi (justification for knowing) üzerine yaptığı vurguyu dikkate alarak Schommer'in inanç sistemine bu boyutu eklerler. Gerekçelendirme boyutundaki naif inançlar bilme eylemine ilişkin otoriteler arasındaki 
uyumu dikkate alırken sofistike inançlar mantık ve kanıt yoluyla bilmenin bireysel düzeyde gerçekleştirilmesi gerekliliğine vurgu yapar. Hofer ve Pintrich'e (1997) göre bu dört boyuttan 'gerekçelendirme' ve 'kaynak' boyutları bireylerin bilmenin doğasına yönelik inançlarını içerir. Öte yandan 'kesinlik' ve 'basitlik' boyutları bilginin doğasına yönelik inançları içerir.

Schommer'in ortaya koyduğu anlayış ciddi derecede eleştirilmektedir. Birincisi yukarıda da belirtildiği üzere bazı boyutların epistemoloji yerine öğrenme ile ilgili olmasıydı ki bu eleştiri kendisi tarafından da kabul edilmiştir. İkinci önemli husus çok boyutlu inanç sisteminin gerçekten var olup olmadığı üzerinedir. Schommer'e göre bireylerin epistemolojik inançları bütün boyutlar için aynı olmak zorunda değildir. Örneğin bilginin kesinliği konusunda naif inançlara sahip olan birisi bilginin kaynağ konusunda sofistike inançlara sahip olabilir. Bu anlayışın gelişimsel perspektifi takip eden araştırmacılar tarafindan kabul edil(e)memesinin altında yatan iki önemli sebep vardır. İlki Schommer'in istatistiksel sonuçları ile ilgilidir. Schommer 5 boyut olduğunu iddia etmiştir ancak bu 5 boyutu aynı anda aynı örneklemde göstermeyi başaramamıştır. Faktör analizleri genellikle 4 boyutlu bir yapı açığa çıkarabilmiştir. İkincisi yöntemsel sorundur. Gelişimsel perspektifi takip eden araştırmacılar genellikle nitel desenlerde boylamsal çalışmalar yapmışlardır. Hatta bazıları kişisel epistemolojinin daha iyi gözlemlendiğini düşündükleri için nitel verileri arasına ikircikli senaryolara karşı katılımcıların tepkilerini ve gerekçelerini de eklemlemişlerdir (Ör. King ve Kitchener, 1994). Onlara göre Schommer'in sadece nicel bir desen ile kesitsel veriler kullanarak öne sürdügü model oldukça iddialıdır. Muis, Trevors, Duffy, Ranellucci ve Foy (2016) lise, lisans ve lisansüstü eğitim düzeyindeki öğrencilerden oluşan bir örneklemde görüşmeler yolu ile veri toplamış ve çok boyutlu yapıyı gözlemleyemediklerini çünkü katılımcıların epistemolojik inanç boyutları arasındaki farklılıkları anlayamadıklarını iddia etmişlerdir. Oysa literatürde yer alan bilimsel çalışmalar nicel ve/veya nitel veriler yolu ile çok boyutlu kuramı destekler görünmektedir. Örneğin Bahcivan ve Cobern (2016) hizmet-içi fen bilimleri öğretmenlerinden oluşan küçük bir örneklemde bir katılımcının bilginin kaynağı konusunda naif inançlara sahip iken diğer boyutlarda sofistike inançlara sahip olduğunu göstermiştir. Benzer sonuçlar aday öğretmenlerle yapılan nitel çalışmalarla da tekerrür etmiştir (Bahçivan, 2016). Katılımcıların epistemolojik boyutlara yönelik farklılıkları algılaması konusunda herhangi bir problem ile karşılaşılmamıştır. Öte yandan lise ve lisans düzeyindeki öğrencilerin katılmış olduğu nicel çalışmalarda da farklı ölçüm araçları kullanılmasına rağmen çok boyutlu inanç sistemini destekler sonuçlarla karşılaş1lmıştır (Bahcivan, 2014; Kapucu ve Bahçivan, 2015).

Aslında Schommer bir eğitim psikoloğudur, gelişimsel perspektifi takip eden araştırmacılar ise çoğunlukla bilişsel psikologdur. $\mathrm{Bu}$ durum önemli bir farklılaşmaya sebep oluyor görünmektedir. Gelişimsel perspektifi takip eden araştırmacılar kişisel epistemolojiyi anlamaya ve modellemeye çaba sarf etmişlerdir. Öte yandan Schommer epistemolojik inançların bireylerin anlama ve kavramasına nasıl etki ettiğine bakmıştır. Bundan dolayıdır ki Schommer için epistemolojik inançlar amaç değil araç konumundadır. Çalışmalarında her zaman istendik yönde olmasa da matematik ve istatistik konusundaki öğrenmelerde öğrencilerin epistemolojik inançlarının etkili olduğunu gösterecek veriler sunabilmiştir. $\mathrm{Bu}$ anlamda Schommer'in çalışmalarının, epistemolojik değişkenleri eğitsel değişkenlerle ilişkilendirme konusunda eğitim literatüründeki araştırmacıların elini kuvvetlendirdiği kabul edilmelidir.

\footnotetext{
Alan Odaklı ya da Bağlam Temelli Perspektif

$\mathrm{Bu}$ iki perspektif birbirinden farklı yaklaşımlara sahip gibi duruyorken benzer bir temel üzerine oturur. O yüzden ikisinin de aynı başlıkta verilmesi uygun görülmüştür. En başta belirtmelidir ki 'alan' kavramı fizik, kimya, psikoloji gibi bilgi alanlarını belirtmektedir. Alan odaklı (domain specific) epistemolojik inanç yaklaşımını benimseyen araştırmacılar kısaca bireylerin alan bağımsız (domain general) epistemolojik inançlara sahip olduğunu ancak bu inançların alanlara odaklanılarak ölçülmeye çalışıldığında farklılıklar gösterebileceğini iddia eder (Buehl, Alexander ve Murphy, 2002). Başka bir ifadeyle bireylerin alan bağımsız epistemolojik inançları, onların herhangi bir özel alana yönelik epistemolojik inançlarını tam anlamıyla yansıtmayabilir (Buehl ve Alexander, 2006). Sözgelimi bir insanın gündelik yaşamında bilgiye
} 
yönelik bakışı açısı sofistike inançlar içeriyorken, aynı kişi matematik alanının kapsadığ bilgiler için naif inançlara sahip olabilir. Örneğin bilginin değişebilen (sofistike) bir oluşum olduğuna inanan bir kişi matematik bilgisinin kesin doğrulardan oluştuğuna (naif) inanabilir. Benzer şekilde Palmer ve Marra (2008) farklı bölümlerde öğrenim görmekte olan üniversite öğrencilerinin doğa ve beşeri bilimlerdeki bilgi ve bilmenin yapısına yönelik inançlarını nitel görüşmeler yolu ile değerlendirmişlerdir. Araştırma sonuçları öğrencilerin \%80'lik bir kısmının bu iki bilimsel alan için farklı epistemolojik inançlara sahip olduğunu göstermiştir. Örneğin doğa bilimlerindeki bilgi beşeri bilimlere göre daha kesin bir bilgi olarak kabul görmüştür.

Hammer ve Elby'nin (2002) alan odaklı inançlar konusunda verdiği etkili bir örnek vardır: Bir insanın bilgiye genel olarak nasıl baktığından hareket ederek fizik bilgisiyle ilgili görüşlerini tahmin edemezsiniz. Böyle bir durum bir golfçüye diğer spor dallarında hangi teknikleri kullandığını sorup, golfü nasıl oynayacağını tahmin etmeye benzer derler. Epistemolojik inançların alanlara göre farklılaşması iki temel nokta üzerinden açıklanmaktadır. Birincisi alansal farklılıkların gerçekte olduğu yönündeki iddiadır. Bireyler genel olarak fen bilimlerindeki bilginin sosyal bilimlerdeki bilgiye göre doğası gereği daha kesin ve değişmez bir yapıya sahip olduğuna inanıyorlar. Bu durum sosyal bilimlerdeki bilgi ile ilgili sofistike inançlara sahip olmalarına sebep olurken fen bilimlerindeki bilgiye yönelik olarak naif inançlara sahip olmalarına sebep olmaktadır (Buehl ve diğerleri, 2002; Muis, Bendixen ve Haerle, 2006). Alan odaklı farklılaşmanın ikinci sebebi bireylerin bu alanlar ile ilgili deneyimlerine dayandırılmaktadır. Bir öğrencinin herhangi bir alandaki öğrenme deneyimleri ikircikli problemlere ya da argümantasyona dayalı yöntemlerle gerçekleşmişse o öğrenci o alanda daha sofistike inançlara sahip olabilir (Palmer ve Marra, 2008). Muis ve diğerleri (2016) farklı eğitim düzeylerindeki öğrencilerin epistemolojik inançlarının alana göre farklılıklar gösterdiğini ancak bu farklılıkların aslında öğrencilerin öğrenme deneyimlerinden kaynaklandığını ifade etmişlerdir. Schommer-Aikins ve Duell (2013) üniversite öğrencilerinden oluşan bir örneklemde epistemolojik inançların yüksek düşünme becerilerine nasıl etki ettiğine bakmışlardır. Çalışmanın sonuçları, katılımcıların matematiksel ön bilgileri istatistiksel olarak sınırlandırıldığında alan bağımsız inançların bu becerileri yordadığını göstermiştir. Dolayısıyla aslında farklılaşan olgu deneyim mi yoksa inanç $\mathrm{m}$ s sorusu hala netlik kazanamamış görünmektedir.

Alan odaklı epistemolojik inançların ölçülmesi konusunda iki farklı yaklaşım vardır: (1) inançlar üzerine disiplin odaklı (disciplinary perspectives on beliefs) yaklaşım ve (2) doğrudan disiplin odaklı inançlar (discipline-specific beliefs) yaklaşımı (Hofer, 2006). Birinci yaklaşımda hali hazırda var olan alan bağımsız ölçek maddelerini ufak eklemelerle disiplin odaklı hale getirirsiniz. Örneğin 'her okuduğuna inanmalısın' şeklindeki bir madde 'fizikte her okuduğuna inanmalısın' şeklinde fizik alanına odaklanır. İkinci yaklaşım ise doğrudan o alanın kendi doğasına odaklanılarak o alana özgü inanç maddeleri geliştirmeyi hedefler. Literatürde bu şekilde geliştirilmiş olan farklı ölçüm araçları mevcuttur. Örnek verecek olursak Conley, Pintrich, Vekiri ve Harrison (2004) tarafından geliştirilen ölçüm aracı ilköğretim öğrencilerinin bilimsel bilginin yapısına yönelik inançlarını doğrudan ölçer ve alan bağımsız maddelerden uyarlanmış bir çalışma değildir.

Bağlam temelli perspektif ise alan odaklı olana çok benzemektedir. Bu yaklaşım, adından da anlaşılacağı üzere epistemolojik inançların bağlamlara göre farklılıklar gösterebileceği iddiasındadır. Yukarıda belirtildiği üzere alan bağımsız epistemoloji literatürüne göre bilginin deneme yanılma yolu ile üretilen, değişken bir yapı olduğuna yönelik inanç sofistike bir inançtır. Ancak bağlam temelli çalışanlar için bu durum çok genel bir yargıyı içerir ve her zaman geçerli olamaz. Örneğin, günümüzde dünyanın yuvarlak olduğu bilgisini tartışmak ve bu bilgiyi değiştirmeye yönelik girişimlerde bulunmak sofistike bir inanışı işaret etmez (Elby ve Hammer, 2001). Çünkü bazı bilgilerin diğerlerine göre daha doğru olduğu tartış1lmaz bir gerçeklik halini almıştır. Sinatra, Kienhues ve Hofer (2014) bilim insanlarının iklim değişikliği konusunda insan etkisini ispatlayacak yeterince delilleri olmamasına rağmen hemen hemen hepsinin iklim değişikliğinin insani etkilerden kaynaklandığını kabul etmesini de bu duruma örnek olarak verir. Yeterince delil olmasa da bazı bilgiler diğerlerinden daha doğru şeklinde 
kabul edilebilir! Elby ve Hammer (2001) bireylerin epistemolojik inançlarındaki bağlamsallıktan bahsederken 'verimlilik' (productivity) adını verdikleri bir kavrama değinirler. Onlara göre bir öğrenci sofistike epistemolojik inançlara sahip olmasına rağmen dersten yüksek not almak için naif inançlara sahip birisi gibi davranabilir. Eğer bir öğretmen derste anlattığ konuların fazla sorgulanmasından rahatsız oluyorsa, o dersteki öğrenciler dersten başarılı sayılmak için öğretmeni rahatsız etmemeyi tercih ediyor olabilir. Oldukça inandırıcı görünen bu senaryonun veri desteğine ihtiyacı vardır. Ayrıca epistemolojik inançların verimlilik adına yaşadığı kaymaların neler olabileceği ve bu inanç kaymalarının bireylerin davranışlarına nasıl etki ettiğinin araştırılması gerekmektedir.

\section{Epistemolojik İnançların Önemi}

Epistemolojik inançları tanımladıktan sonra bu inançların eğitim çalışmaları açısından neden önemli olduğunun açıklanması gerekmektedir. Aslında cevap çok basit: epistemolojik inançlarımız öğrenme ve öğretim inançlarımız açısından görece daha merkezi bir konumdadır (Brownlee, Boulton-Lewis ve Purdie, 2002; Hofer ve Pintrich, 1997). Başka bir ifadeyle epistemolojik inançlar hem öğrenenin hem de öğretenin kendisine iş edindiği eylemi nasıl gerçekleştireceği konusunda belirleyici konumdadır denilebilir.

Ampirik çalışmalar faklı düzeylerdeki ögrencilerin sofistike epistemolojik inançlarının başarı ve kavramsal anlamalarını etkilediğini göstermektedir. Örneğin, Hofer (2000) üniversite öğrencilerinin epistemolojik inançlarının onların psikoloji dersindeki başarılarını yordadığını göstermiştir. Psikoloji bilgisinin basit ve kesin olduğuna inanan (naif inançlar) öğrencilerin başarı puanlarının düşük olduğunu göstermiştir. Benzer şekilde Stathopoulou ve Vosniadou (2007) sofistike (epistemolojik) inançlara sahip olan lise öğrencilerinin naif inançlara sahip olan öğrencilere göre 'kuvvet ve hareket' konusunda daha başarılı olduğunu göstermiştir. Bazı araştırmacılar (Duit ve Treagust, 2003; Qian ve Alvermann, 1995) epistemolojik inançların öğrencilerin kavramsal değişime yönelik hazırbulunuşluklarını (readiness to conceptual change) etkileyebileceğine dikkat çekmişlerdir. $\mathrm{Bu}$ durum 5. sınıf düzeyinde yapılan deneysel çalışmaların sonuçları ile de doğrulanmıştır (Mason, Gava ve Boldrin, 2008).

Şu ana kadar epistemolojik inançların öğrenme üzerine ne gibi etkileri olduğundan kısaca bahsedilmiştir. Bu noktada epistemolojik inançların öğrenme üzerinde neden ve nasıl etkili olduklarına da değinmek gerekmektedir. Cano (2005) lise öğrencilerinin başarılarının epistemolojik inançlarından etkilendiğini ancak bu etkileşimin aracı bir değişken sayesinde gerçekleştiğini göstermiştir. $\mathrm{Bu}$ aracı değişken öğrenme yaklaşımıdır (learning approach). Epistemolojik inançları daha sofistike olan bireyler bilginin göreliliğinin farkında olduğu için naif olanlara göre daha fazla gerekçe üretmek durumunda kalıyorlar. Daha fazla kaynağa ulaşıp bilginin daha etkili bir şekilde gerekçelendirilmesini sağlayacak öğrenme yaklaşımlarını benimsiyorlar. Muis (2007) ise epistemolojik inançların öz düzenlemeli öğrenme (self-regulated learning) üzerine etkisini gösteren teorik bir model oluşturmuştur. Daha açık bir ifadeyle, bu modele göre epistemolojik inançlar bireylerin başarıları üzerinde etkilidir; çünkü bu inançlar bireylerin bir öğrenme olgusunu nasıl tanımladığını, hangi öğrenme standartlarını seçtiğini, biliş-ötesi süreçleri (metacognitive processes) nasıl belirlediğini ve öğrenme süreçlerini nasıl değerlendirdiğini etkilemektedir. Ardışık çalışmalarda Muis ve arkadaşları bu modeli üniversite öğrencilerinden elde ettikleri veriler yoluyla doğrulamıştır (Muis, 2008; Muis ve Franco, 2009; Muis ve Franco, 2010). Muis'in çalışmalarını dikkate alan Bromme, Pieschl ve Stahl (2010) benzer bir model öne sürerler: anlama ve ayarlama hipotezi (apprehension and calibration hypothesis). Bu hipoteze göre de sofistike epistemolojik inançlar bireylerin öğrenme alanlarına uygun öğrenme yaklaşımlarını etkili bir şekilde kullanmalarını sağlamaktadır. Muis ve arkadaşları son çalışmalarında yukarıda belirtilen değişkenlere epistemik duyguları da eklemiştir (Trevors ve diğerleri, 2016; Muis ve diğerleri, 2015). Buna göre üniversite öğrencilerinin epistemolojik inançları önce epistemik duyguları (epistemic emotions [kayg1, heyecanlanma, meraklanma vb.]) harekete geçiriyor, bu duygular öğrenme stratejilerini belirliyor. Öğrenme stratejileri ise öğrencilerin iklim değişikliği konusunu kavrama düzeylerini etkiliyor görünmektedir. 
Epistemolojik inançların aday ya da hizmet-içi öğretmenler üzerindeki etkisini de kısaca açıklamak gerekmektedir. Öncelikle belirtilmesi gereken önemli bir nokta var. Duffy ve diğerlerinin (2016) yaptığı çalışma üniversite öğrencilerinin epistemolojik inançlarının ve öğrenme-öğretme yaklaşımlarının öğretmenin epistemolojik inançlarından etkilendiğini göstermektedir. Bu bağlamda bir öğretmenin epistemolojik inançlarının bir domino etkisini yapabileceğini akıldan çıkarmamak gerekir. Peki, bir öğretmenin epistemolojik inançları kendisini nasıl etkiliyor? Veriler aday ve hizmet-içi öğretmenlerin epistemolojik inançlarının her zaman istendik yönde olmasa da öğrenme-öğretme anlayışlarını (conceptions of learning and teaching) etkilediğini göstermektedir (Chan ve Elliott, 2004). Daha açık ifade etmek gerekirse bir öğretmen sofistike epistemolojik inançlara sahip olduğunda öğrencinin daha aktif olduğu (daha yapılandırmacı da diyebiliriz) öğrenme ve öğretme anlayışlarını benimseyebiliyor. Deneyimli fen bilimleri öğretmenleri ile yapılan nitel bir araştırmada öğretmenlerin epistemolojik inançlarında naiften sofistike olana doğru bir kayma yaşandığında öğretmenlerin öğrenme-öğretme anlayışlarında yapılandırmacı yaklaşımı tercih ettiğini ve bu öğretmenlerin öğrenme-öğretme öz yeterliklerinin daha güçlü olduğunu görülmüştür. Sınıf içi gözlemler ise öğretmenlerin bu inançlarının öğretim uygulamalarına doğrudan etki ettiğini göstermiştir (Bahcivan ve Cobern, 2016). Ancak benzer bir çalışma fen bilimleri öğretmen adayları ile yapıldığında sonuçlar şaşırtıcı derecede farklılaşmıştır. Aday öğretmenlerde epistemolojik inançlar öğrenme-öğretme anlayışları üzerindeki etkinliğini yitirmiş, katılımcıların geçmiş tecrübeleri ve öz yeterlik inançları belirleyici olmuştur (Bahçivan, 2016). Benzer sonuçlar başka bir araştırmada da tekrar etmiştir (Güneş ve Bahçivan, 2016). Farklı bir çalışmanın sonuçları ise fen bilimleri öğretmen adaylarının bilmenin doğasına yönelik inançlarının fen öğretim öz yeterliklerini yordadığını göstermiştir (Bahcivan, 2014). Sonuçların her zaman istendik yönde çıkmamasının altında yatan temel sebebin ise kültürel farklılaşmalar olabileceğine yönelik güçlü iddialar (Chan ve Elliott, 2004; Hofer, 2008) ve veriler (Bahcivan ve Cobern, 2016) vardır.

\section{Gelecek Perspektifler}

Öncelikle belirtilmesi gerekir ki yukarıda incelemesi sunulan literatür oldukça özet sayılır, yine de altı çizilmesi gereken durumlar mümkün olduğunca geniş bir bakış açısı ile verilmeye çalışılmıştır. 'Bu alanda neleri çalışmamız gerekir?' sorusuna verilecek ilk cevap kendi kültürümüzdeki boylamsal (5-10 y1l gibi uzun süreli) ya da karma desenli çalışmalara duyulan ihtiyaç şeklindedir. Özellikle gelişimsel perspektifte yer alan epistemolojik modellerin verileri Batı toplumlarından gelmektedir. Ancak bugün epistemoloji alanındaki araştırmacılar bile bilginin ve inançların bağlamsal bir perspektifle ele alınması gerektiğini belirtmektedirler (Hofer, 2008). Kültür bilindiği gibi en önemli bağlamlar arasında yer alır. Batı kültüründe otoritelerin devamlı sorgulanması ve otoriteye güvensizlik gelişmiş bir epistemolojik inanç olarak kabul edilmektedir. Peki, Türk kültüründe de aynı durum geçerli midir? Bu soruya net bir cevap vermek için boylamsal çalışmalara ihtiyaç vardır. Bu konuda yapılabilecek bir şey daha var: sosyal psikolojinin değişkenlerinin eğitim araştırmalarına eklemlenmesi gerekmektedir. Çalışmanın yazarı bu çalışmanın kaynakçasında yer alan araştırmalarının önemli bir kısmında 'benlik kurgusu' kavramını kullanmıştır. Benlik kurgusu sosyal psikolojinin önemli kavramlarından birisidir ve kültürel bağlamdan belirgin bir şekilde etkilenen merkezi inançları içerir (Kağıtçıaşı, 2007).

Epistemoloji literatürü örtük bir şekilde alan bağımsız epistemolojik inançların olmadığına, aslında bütün epistemolojik inançların alan bağımlı ya da bağlam temelli olduğu yönündeki hipotezleri destekler sonuçlar üretmeye başladı. Dikkat edecek olursanız epistemoloji alanındaki perspektifler arasında da alan bağımlı ya da bağlam temelli perspektifler en sonda gelmektedir. Örtük bir şekilde gidiliyor gibi duran bu problemin cevabını üretmek için kendi alanında uzman (örneğin profesörler) yetişkinlerin nitel araştırmalar yolu ile sorgulanması önerilebilir. Örneğin bir fizik profesörünün ve bir tarih profesörünün kendi alanındaki epistemolojik inançları ve karşıt alandaki (örneğin fizikçi için tarih) epistemolojik inançları görüşmeler yoluyla sorgulanabilir. Bu gibi sorgulamalar muhtemelen fizikçinin kendi alanında sofistike inançlara sahip olduğunu, tarih alanında ise bilgisi nispeten yetersiz olduğu için daha 
naif inançlara sahip olduğunu gösterecektir. Sonuçlar bu şekilde çıkarsa şaşırtıcı olmayacaktır ama ya tersi çıkarsa! Fizikçi kendi alanındaki bilgiye hakim olduğu için daha naif inançlara, tarih alanında ise bilgi düzeyindeki eksikliklerinden dolayı daha sofistike inançlara sahip olabilir. Her iki durum da mümkündür ve epistemolojik inançların aslında alan bağımlı ya da bağlam temelli olduğunu gösterir. Çünkü bireylerin gerçekte neyi, nasıl ve ne kadar bildiği o alandaki inançları şekillendiriyor görünmektedir. Bununla beraber alan bağımlı literatür oldukça genişlemiş olmakla birlikte bağlam temelli olanın hala yeni bakış açılarına ihtiyacı olduğu da açıktır. Yukarıda 'verimlilik' adına epistemolojik inançlarına uygun hareket etmeyen bireyler olabileceğini tartışmıştık. Acaba bir öğrenciyi epistemolojik açıdan sıkıştıran başka hangi bağlamlar vardır? Öğrenme ortamlarının bu gözle incelenmesi öğretmen eğitimi literatürüne katkılar sunabilir.

Bir başka çalışma alanı ise bireysel epistemolojinin nasıl geliştirileceği üzerine kurgulanabilir. Mademki epistemolojik inançlarımız nasıl öğreneceğimizi veya nasıl öğreteceğimizi belirleyen bir etken o halde epistemolojik inançların istendik yönde nasıl destekleneceğinin araştırılması gerekir. Literatür bu konuda derin değildir. Yüzeysel bazı çalışmalar var ancak hala basamakları belli olan anlaşılır eğitim modelleri yok. Bu konuda argümantasyonun bir öğretim yöntemi olarak etkili olabileceği düşünülebilir. Argümantasyon, öğrenenlerin sürekli iddialar ortaya attığı, iddialarını veriler yolu ile destekledikleri ve çoğu zamanda karşıt iddiaları çürütmek durumunda kaldıkları bir sorgulama ve bilgi oluşturma sürecidir denilebilir. Böyle bir ortamda bireyler bilginin göreliliğine ve karmaşık yapısına tanık olmaktadır (Newton, Driver ve Osborne, 1999). Dolayısıyla argümantasyonun epistemolojik gelişimi destekleyecek eğitim modelleri oluşturmak adına iyi bir başlangıç olabileceği düşünülebilir. Argümantasyon ve epistemolojik bakış açıları arasındaki ilişkilerin kapsamlı bir şekilde anlaşılabilmesi için D. Kuhn' un (1991) çalışmalarından faydalanılabilir.

Son olarak, epistemolojik inançların öğrenme üzerine olan etkileri nedensellikleri ile birlikte epeyce araştırılmış görünüyor ancak aynı durum öğretim inançları ve pratikleri için geçerli değildir. Öğretmenlerin epistemolojik inançlarının öğretim inançlarına neden ve nasıl etki ettiğinin araştırılması gerekmektedir. Öğrenmede olduğu gibi öğretimde de epistemolojik inançlar ve öğretim arasındaki etkileşime aracılık yapan bazı değişkenler olabilir. Bu aracı değişkenlerin bulunması öğretmen yetiştirme literatürüne değerli katkılarda bulunacaktır.

\section{Kaynaklar}

Bahcivan, E. (2014). Examining relationships among Turkish pre-service science teachers' conceptions of teaching and learning, scientific epistemological beliefs and science teaching efficacy beliefs. Journal of Baltic Science Education, 13(6), 870-882.

Bahcivan, E. ve Cobern, W. W. (2016). Investigating coherence among Turkish elementary science teachers' teaching belief systems, pedagogical content knowledge and practice. Australian Journal of Teacher Education, 41(10), 62-86.

Bahçivan, E. (2016). Investigating the relationships among PSTs' teaching beliefs: are epistemological beliefs central? Educational Studies, 42(2), 221-238.

Baxter Magolda, M. B. (1992). Knowing and reasoning in college: Gender-related patterns in students' intellectual development. San Francisco: Jossey Bass.

Belenky, M. R, Clinchy, B. M., Goldberger, N. R. ve Tarule, J. M. (1986). Women's ways of knowing: The development of self voice and mind. New York: Basic Books.

Bendixen, L. D. (2002). A process model of epistemic belief change. B. K. Hofer ve P. R. Pintrich (Yay. haz.). Personal Epistemology: The Psychology of Beliefs içinde (s. 191-208). London: Lawrence Erlbaum Associates Publishers.

Bromme, R., Pieschl, R. ve Stahl, E. (2010). Epistemological beliefs are standards for adaptive learning: a functional theory about epistemological beliefs and metacognition. Metacognition Learning, 5, 7-26.

Brownlee, J., Boulton-Lewis, G. ve Purdie, N. (2002). Core beliefs about knowing and peripheral beliefs about learning: developing an holistic conceptualisation of 
epistemological beliefs. Australian Journal of Educational \& Developmental Psychology, 2, 1-16.

Buehl, M. M. ve Alexander, P. A. (2006). Examining the dual nature of epistemological beliefs. International Journal of Educational Research, 45, 28-42.

Buehl, M. M., Alexander, P. A. ve Murphy, P. K. (2002). Beliefs about schooled knowledge: domain specific or domain general? Contemporary Educational Psychology, 27, 415449.

Cano, F. (2005). Epistemological beliefs and approaches to learning: Their change through secondary school and their influence on academic performance. British Journal of Educational Psychology, 75, 203-221.

Chan, K. W. ve Elliott, R. G. (2004). Relational analysis of personal epistemology and conceptions about teaching and learning. Teaching and Teacher Education, 20(8), 817831.

Conley, A. M., Pintrich, P. R., Vekiri, L. ve Harrison, D. (2004). Changes in epistemological beliefs in elementary science students.Contemporary Educational Psychology, 29, 186204.

Cevizci, A. (2010). Bilgi felsefesi. İstanbul: Say Yayınları.

Duffy, M. C., Muis, K. R., Foy, M. J., Trevors, G. ve Ranellucci, J. Exploring Relations between Teachers' Beliefs, Instructional Practices, and Students' Beliefs in Statistics. International Educational Research, 4(1), 37-66.

Duit, R. ve Treagust, D.F. (2003). Conceptual change: s powerful framework for improving science teaching and learning. International journal of Science Education, 25(6), 671688.

Elby, A. ve Hammer, D. (2001). On the Substance of a Sophisticated Epistemology. Issues and Trends, 85, 554-567.

Güneş, E. ve Bahçivan, E. (2016). A multiple case study of preservice science teachers' TPACK: embedded in a comprehensive belief system. International Journal of Environmental and Science Education, 11(15), 8040-8054.

Hammer, D. ve Elby, A. (2002). On the form of a personal epistemology. B. K. Hofer ve P. R. Pintrich (Yay. haz.). Personal Epistemology:The Psychology of Beliefs içinde (s. 169190). London: Lawrence Erlbaum Associates Publishers.

Hofer, B. K. (2008). Personal epistemology and culture. M. S. Khine, (Yay. haz.). Knowing, Knowledge and Beliefs. Epistemological Studies across Diverse Cultures içinde (s. 322). Springer Science + Business Media B.V.

Hofer, B. K. (2006). Domain specificity of personal epistemology: resolved questions, persistent issues, new models. International Journal of Educational Research, 45, 85-95.

Hofer, B. K. (2000). Dimensionality and disciplinary differences in personal epistemology. Contemporary Educational Psychology, 25, 378-405.

Hofer, B. K. ve Pintrich, P. R. (2002). Personal epistemology: The psychology of beliefs about knowledge and knowing. Mahwah, NJ: Erlbaum.

Hofer, B. K. ve Pintrich, P. R. (1997). The development of epistemological theories: Beliefs about knowledge and knowing and their relation to learning. Review of Educational Research, 67, 88-140.

Kağıtçıbaşı, Ç. (2007). Family, self, and human development across cultures, theory and applications (2nd ed.). London: Lawrence Erlbaum Associates.

Kapucu, S. ve Bahçivan, E. (2015). High school students' scientific epistemological beliefs, self-efficacy in learning physics and attitudes toward physics: A structural equation model. Research in Science \& Technological Education, 33(2), 252-267.

King, P. M. ve Kitchener, K. S. (2004). Reflective judgment: Theory and research on the development of epistemic assumptions through adulthood. Educational Psychologist, $39(1), 5-18$. 
King, P. M. ve Kitchener, K. S. (1994). Developing reflective judgment: Understanding and promoting intellectual growth and critical thinking in adolescents and adults. San Francisco: Jossey-Bass.

Kuhn, D. (1991). The skills of argument. Cambridge, England: Cambridge University Press.

Kuhn, D., Iordanou, K., Pease, M. ve Wirkala, C. (2008). Beyond control of variables: What needs to develop to achieve skilled scientific thinking? Cognitive Development, 23, 435451.

Mason, L., Gava, M. ve Boldrin, A. (2008). On warm conceptual change: the interplay of text, epistemological beliefs, and topic interest. Journal of Educational Psychology, 100(2), 291-309.

Muis, K. R. (2008). Epistemic profiles and self-regulated learning: Examining relations in the context of mathematics problem solving. Contemporary Educational Psychology, 33, $177-208$.

Muis, K. R. (2007). The role of epistemic beliefs in self-regulated learning. Educational Psychologist, 42, 173-190.

Muis, K. R., Bendixen, L. D. ve Haerle, F. C. (2006). Domain-generality and domain specificity in personal epistemology research: Philosophical and empirical reflections in the development of a theoretical framework. Educational Psychology Review, 18(1), 3-54.

Muis, K. R. ve Franco, G. M. (2010). Epistemic profiles and metacognition: support for the consistency hypothesis. Metacognition Learning, 5, 27-45.

Muis, K. R. ve Franco, G. M. (2009). Epistemic beliefs: Setting the standards in self-regulated learning. Contemporary Educational Psychology, 34, 306-318.

Muis, K. R., Pekrun, R., Sinatra, G. M., Azevedo, R., Trevors, G., Meier, E. ve Heddy, B. C. (2015). The curious case of climate change: Testing a theoretical model of epistemic beliefs, epistemic emotions, and complex learning. Learning and Instruction, 39, 168183.

Muis, K. R., Trevors, G., Duffy, M., Ranellucci, J. ve Foy, M. J. (2016). Testing the TIDE: examining the nature of students' epistemic beliefs using a multiple methods approach. The Journal of Experimental Education, 84(2), 264-288.

Newton, P., Driver, R. ve Osborne, J. (1999). The place of argumentation in the pedagogy of school science. International Journal of Science Education, 21(5), 553-576.

Palmer, B. ve Marra, R. M. (2008). Individual domain-specific epistemologies: 1mplications for educational practice. M. S. Khine (Yay. haz.). Knowing, Knowledge and Beliefs. Epistemological Studies across Diverse Cultures içinde (s. 325-350). Springer Science + Business Media B.V.

Perry, W. G. (1970). Forms of intellectual and ethical development in the college years: A scheme. New York: Holt, Rinehart and Winston.

Piaget, J. (1970). Genetic epistemology. New York: Columbia University Press.

Qian, G. ve Alvermann, D. (1995). Role of epistemological beliefs and learned helplessness in secondary school students' learning science concepts from text. Journal of Educational Psychology, 87(2), 282-292.

Schommer, M. (1994). An emerging conceptualization of epistemological beliefs and their role in learning. R. Garner ve P. Alexander (Yay. haz.). Beliefs about text and about text instruction içinde (s. 25-39). Hillsdale, NJ: Erlbaum.

Schommer, M. (1990). Effects of beliefs about the nature of knowledge on comprehension. Journal of Educational Psychology, 82, 498-504.

Schommer-Aikins, M. (2004). Explaining the epistemological belief system: Introducing the embedded systemic model and coordinated research approach. Educational Psychologist, 39(1),19-29.

Schommer-Aikins, M. ve Duell, O.K. (2013). Domain specific and general epistemological beliefs. Their effects on mathematics. Revista de Investigación Educativa, 31(2), 317330 . 
Sinatra, G. M., Kienhues, D. ve Hofer, B. K. (2014). Addressing challenges to public understanding of science: Epistemic cognition, motivated reasoning, and conceptual change. Educational Psychologist, 49(2), 123-138.

Stathopoulou, C. ve Vosniadou, S. (2007). Exploring the relationship between physics-related epistemological beliefs and physics understanding. Contemporary Educational Psychology, 32, 255-281.

Trevors, G. J., Muis, K. R., Pekrun, R., Sinatra, G. M. ve Muijselaar, M. M. (2016). Exploring the relations between epistemic beliefs, emotions, and learning from texts. Contemporary Educational Psychology.

\section{Extended Abstract}

\section{Introduction}

Epistemology is the branch of philosophy related to knowledge and knowing. Studies of (educational) psychologists have shifted the epistemological studies to investigate how people come to learn and what they think about the structure of knowledge for approximately 50 years. In this era, as parallel to progresses in technology, not only abundance but also pollution of knowledge was critically increasing, therefore, people's personal epistemology takes many researchers' attention on this area. This study was conducted to investigate this literature by a critical manner. Three research questions were explored. 1) What are the epistemological traditions in the literature? 2) Why do education researchers put effort to investigate personal epistemology? 3) What can be presented as future perspectives related to educational epistemology?

\section{Traditions}

There are three different research traditions in personal epistemology. The first has a developmental perspective which claims that personal epistemology shifts to advanced positions by physiological progress and social interactions. To this tradition people, at the beginning (in dualistic position), view knowledge as absolute truths or wrongs. In a further position called as multiplistic, people think that some grey areas are possible between absolute truths and wrongs, but they still think that an absolute truth is reachable. During the relativistic position, people believe that everyone constructs their own knowledge by justification, so there are multiple solutions of any problem. In the last stage called as commitment within relativism, people believe that there are multiple perspectives in terms of knowledge and knowing, but one of the alternatives is better than the others and justification assists this decision making processes. In contrast to the developmental perspective, multidimensional perspective claims that personal epistemology involves people's epistemological beliefs which are more or less independent. Certainty, simplicity, source and justification have been proposed as the epistemological belief dimensions by scientists. Certainty and simplicity involve beliefs about structure of knowledge whereas source and justification cover the beliefs about knowing. Although, studies of multidimensional researchers have been criticized by development researchers due to quantitative nature of research designs, it is clear that these quantitative designs contributed educational studies in terms of investigating possible relations between educational and epistemological variables. The last tradition about personal epistemology proposes that people hold domain general epistemological beliefs but these beliefs can be particularized in accordance to specific domains. For example, people may believe that knowledge in humanities is not certain as much as the one in mathematics. Also, context of knowledge and knowing may experience epistemological beliefs to present certain shifts. For example, believing that the knowledge of 'The Earth has a shape of geoid' is not certain does not correspond to a sophisticated epistemological belief. 


\section{Importance of Epistemological Beliefs}

When it comes to the second research question, a plethora of researchers have claimed that people's epistemological beliefs have a central position in accordance to their teaching and learning behaviors. Researchers also provided different types of evidences approving that people's epistemological beliefs are effective on their teaching-learning beliefs. In general, a student holding more sophisticated epistemological beliefs not shot higher achievement scores than their naïve peers. Also, sophisticated students have readiness for conceptual in accordance to their naïve peers. Because, their epistemological beliefs interrelate with their learning approaches and strategies, epistemic emotions, and/or self-regulated learning tenets. Furthermore, pre-/in-service teachers' epistemological beliefs are effective on their teaching beliefs. In short, their sophisticated epistemological beliefs, though not always, make them to hold more constructivist teaching and learning conceptions as well as hold more self-efficacious beliefs of teaching. Just a few research studies declared opposite relations between epistemological and teaching/learning beliefs. These studies speculated that cultural differences between east and west societies are responsible for these unexpected results.

\section{Future Perspectives}

Regarding the third research question, I, firstly, suggest following researchers to conduct longitudinal research studies to catch possible effects of cultural contexts on their citizens' personal epistemology. Also, domain or context dependency of epistemological beliefs needs further investigations since they are the last traditions in this area. In addition, interventions contributing individuals' epistemological development should be explored. In this regard, argumentation seems as a better candidate. Finally, the literature presents the relations between epistemological beliefs and learning variables together with reasons, however, still lacks of research studies evidencing why teachers' epistemological beliefs are effective on their teaching and learning conceptions. 